\title{
Estudo da produção de $\beta$-lactamase e sensibilidade às drogas em linhagens de estafilococos coagulase-negativos isolados de recém-nascidos
}

\author{
Study of production of $\beta$-lactamase and drugs susceptibility in strains of coagulase-negative staphylococci \\ isolated of neonates
}

Maria de Lourdes Ribeiro de Souza da Cunha' Carlos Alberto de Magalhães Lopes ${ }^{2}$

\begin{tabular}{c|l}
\begin{tabular}{c|l} 
unitermos \\
Estafilococos coagulase-
\end{tabular} & $\begin{array}{l}\text { } \text { Os estafilococos coagulase-negativos (ECN), embora reconhecidos como saprófitas por muito } \\
\text { negativos }\end{array}$ \\
$\begin{array}{c}\text { tempon têm emergido como agentes etiológicos de uma série de infecções, sendo atualmen- } \\
\text { te os principais responsáveis por sepse em UTI neonatal. Tendo em vista estas características, } \\
\text { antimicrobianos }\end{array}$ & $\begin{array}{l}\text { este estudo objetivou a identificação de estafilococos coagulase-negativos isolados de } \\
\text { processos infecciosos em recém-nascidos, bem como a determinação da produção de } \\
\text { Recém-nascidos } \\
\text { foi a espécie mais freqüentemente isolada (77,8\%). O estudo da produção de } \beta \text {-lactamase } \\
\text { revelou esta característica na maioria das linhagens de ECN isoladas (71,8\%). As linhagens } \\
\text { de ECN mostraram, ainda, resistência múltipla aos antibióticos utilizados, com 63,2\% } \\
\text { dos isolados apresentando resistência a cinco ou mais drogas. A elevada transmissibilidade } \\
\text { de plasmídios entre estas linhagens e o uso abusivo de drogas antimicrobianas têm-se } \\
\text { constituído em importantes fatores na seleção de amostras multirresistentes e na transferência } \\
\text { de genes de resistência. }\end{array}$
\end{tabular}

abstract

Although coagulase-negative staphylococci (CNS) have been recognized as saprophytes for a long time, they had emerged as etiologic agents of infections. They have currently been the most frequently isolated pathogen in sepsis in neonatal intensive care unit (NICU). This study aimed the identification of CNS strains isolated from newborns' infections and to determination of $\beta$-lactamase and drugs susceptibility. Staphylococcus epidermidis was the most frequently isolated species $(77,8 \%)$. The study of the $\beta$-lactamase production revealed this characteristic in the most of the strains of CNS isolated $(71,8 \%)$. The strains isolated in this study presented multiple resistance to the antibiotics tested, with $63,2 \%$ of isolates presenting resistance to five or more drugs. The high transmissibility of plasmids among those strains and the abusive use of drugs antimicrobial has been constituting in important factors to the selection of multi-resistance samples and the transfer of resistance genes. key words

Coagulase-negative

staphylococci Antimicrobial susceptibility Neonates

\section{Introdução}

Os estafilococos coagulase-negativos (ECN) são a maior causa de bacteremia adquirida no ambiente hospitalar, na maioria dos casos em pacientes mantidos em unidades de tratamento intensivo (UTI) e UTI neonatal $(17,21)$. Estes microrganismos apresentam elevado risco potencial de bacteremia nosocomial em recém-nascidos de baixo peso, os quais são imunologicamente imaturos e freqüentemente requerem procedimentos invasivos para administração de substâncias nutritivas e medicamentosas (12).

Relativamente às espécies com maior freqüência percentual nas bacteremias, alguns pesquisadores re-
1. Doutora; professora assistente do Departamento de Microbiologia e Imunologia Instituto de Biociências Unesp/Botucatu. 2. Professor titular do Departamento de Microbiologia e Imunologia - Instituto de Biociências - Unesp/Botucatu. Fonte financiadora: Fapesp. 
velam que o S. epidermidis tem sido isolado de $74 \%$ a $92 \%$ dos pacientes com o processo adquirido no ambiente hospitalar (12).

O S. saprophyticus é um patógeno importante em infecções do trato urinário humano, especialmente em muIheres jovens e sexualmente ativas (15), além de estar relacionado como agente etiológico de uretrite e prostatite em homens (25) e em processos septicêmicos (10).

O S. haemolyticus é a segunda espécie mais freqüentemente encontrada entre os ECN, sendo associado a várias infecções (18), como endocardites em válvula natural, septicemias, peritonites, infecções do trato urinário, em feridas, nos ossos e nas articulações $(17,29)$. Outras espécies, como S. lugdunensis, S. hominis, S. warneri, S. capitis, S. simulans, S. cohnii, S. xylosus e S. saccharolyticus, também têm sido associadas a feridas infectadas, abscessos, endocardites, pneumonias, osteomielites, septicemias e infecções associadas a cateteres e próteses (17).

Com o crescimento da caracterização de infecção por ECN, o interesse em estudar sua suscetibilidade a vários antimicrobianos também tem proporcionalmente aumentado (17). Segundo Archer \& Climo (3) e Jones (14), há uma associação entre o aumento da freqüência percentual dos ECN na etiologia de bacteremia nosocomial e a resistência desses microrganismos aos agentes antimicrobianos. As linhagens isoladas de espécimes clínicos têm se revelado freqüentemente resistentes aos antibióticos comumente usados no âmbito hospitalar $(11,14)$. A elevada transmissibilidade de plasmídios entre estas linhagens e o uso abusivo de drogas antimicrobianas têm se constituído em importantes fatores na seleção de amostras multirresistentes e à transferência de genes de resistência (28).

Os ECN de infecções nosocomiais, particularmente o S. epidermidis e o $S$. haemolyticus, apresentam freqüência percentual em geral maior que $80 \%$ de resistência à meticilina (11). Quando os ECN são multirresitentes aos antibióticos comumente usados, o glicopeptídeo vancomicina tem sido considerado o antibiótico de escolha (17). Entretanto Veach et al. (29) isolaram linhagens de $S$. haemolyticus resistentes à vancomicina de pacientes submetidos a terapia prolongada com este antimicrobiano. As linhagens de $S$. haemolyticus isoladas dos pacientes em tratamento com vancomicina mostraram uma diminuição na suscetibilidade a esta droga, quando comparadas com as linhagens isoladas antes da antibioticoterapia (29). Embora sejam raras, estas linhagens podem ser o sinal do início da resistência a um importante antibiótico usado no tratamento das infecções estafilocócicas.
Por outro lado, a redução na suscetibilidade à teicoplanina também tem sido relatada por Bannerman et al. (5) em linhagens de S. epidermidis e S. haemolyticus. Estes autores, em estudo realizado nos Estados Unidos, verificaram que $7 \%$ das linhagens de S. epidermidis e $21 \%$ das de S. haemolyticus apresentaram sensibilidade moderada à teicoplanina, enquanto que $11 \%$ dos S. haemolyticus foram resistentes. Porém os mecanismos genéticos e bioquímicos responsáveis pela resistência dos ECN aos glicopeptídeos não estão completamente elucidados (8). Essa resistência não tem se mostrado transmissível entre eles, não obstante pressões seletivas possam influenciar o desenvolvimento de resistência entre linhagens de um paciente infectado pelo ambiente hospitalar.

Considerando que a prevalência desses microrganismos e suas suscetibilidades às drogas diferem em diversos ambientes hospitalares e regiões, decidimos avaliar esta questão em nosso âmbito, determinando como objetivos principais a identificação das espécies de ECN isoladas de casos clínicos de recém-nascidos da unidade neonatal do Hospital das Clínicas da Faculdade de Medicina de Botucatu (Unesp), bem como a determinação da produção de $\beta$-lactamase e a sensibilidade antimicrobiana in vitro às drogas pelas diferentes linhagens isoladas.

\section{Materiais e métodos}

\section{Linhagens}

Foram estudadas 117 linhagens de estafilococos coagulase-negativos (ECN) isoladas de fluidos internos, incluindo sangue, urina e secreções, bem como de corpos estranhos, como cânulas, drenos e cateteres infectados, provenientes de 107 recém-nascidos internados na unidade neonatal do Hospital das Clínicas da Faculdade de Medicina de Botucatu.

Nos casos de material biológico em que se encontra uma microbiota normal e cujos ECN estiveram em cultura associativa com outras bactérias, exigiu-se sempre sua nítida prevalência numérica.

\section{Identificação de estafilococos coagulase-negativos}

Os isolados obtidos a partir de espécimes clínicos foram semeados em ágar sangue e corados pelo método de Gram, objetivando-se sua pureza e a observação de sua morfologia e coloração específica. Após a confirmação destas características, as linhagens foram submetidas às 
provas de catalase e coagulase. O gênero Staphylococcus foi diferenciado de Micrococcus com base na prova de oxidação e fermentação da glicose (9), pela resistência à bacitracina $(0,04 \mathrm{U})$, indicada pela ausência de halo de inibição ou formação de halo de até $9 \mathrm{~mm}$, e pela sensibilidade à furazolidona $(100 \mathrm{mg})$, caracterizada por halos de inibição de $15 \mathrm{~mm}$ a $35 \mathrm{~mm}$ de diâmetro (4).

Para a identificação dos estafilococos coagulase-negativos foram seguidos os critérios propostos por Kloos \& Schleifer (16) e Kloos \& Bannerman (18), conforme esquema simplificado de provas bioquímicas, os quais estabelecem a realização de testes de utilização de açúcares: xilose, arabinose, sacarose, trealose, manitol, maltose, lactose, xilitol, ribose e frutose, bem como caracterização de hemolisinas, redução de nitrato, urease, ornitina decarboxilase e resistência a novobiocina.

\section{Produção de $\beta$-lactamase}

A produção de $\beta$-lactamase foi detectada pelo uso de palitos impregnados com Nitrocefina (cefalosporina cromogênica - Oxoid Diagnostic Reagents). As linhagens a serem estudadas foram semeadas em ágar sangue de forma a se obterem colônias isoladas que, após incubação a $37^{\circ} \mathrm{C}$ por 24 horas, foram tocadas pelos palitos impregnados com Nitrocefina para coletar uma pequena massa de crescimento bacteriano. A seguir, os palitos foram deixados entre a tampa e a base da placa invertida. Como a reação requer umidade, as tampas que não tinham água de condensação receberam uma ou duas gotas de água destilada, e após cinco minutos os palitos foram analisados quanto aos resultados. A reação positiva foi evidenciada pelo desenvolvimento de uma coloração vermelha, e a negativa, pela não-alteração de cor. Para as linhagens $\beta$-lactamase negativas, a reação foi reexaminada após uma hora, conforme recomendações do fabricante. Para a correta análise dos resultados, os palitos em teste foram sempre comparados a um palito não-usado.

\section{Estudo da sensibilidade às drogas antimicrobianas}

O teste de sensibilidade às drogas antimicrobianas foi realizado pela técnica da difusão da droga em ágar a partir de discos impregnados, conforme critérios recomendados pelo National Committee for Clinical Laboratory Standards (NCCLS) (24). Para o preparo dos inóculos foram utilizadas culturas em caldo $\mathrm{BHI}$, previamente incubadas por quatro a seis horas e ajustadas anteriormente com a turbidez da escala 0,5 de McFarland. Os discos utilizados foram: penicilina $G(10 \mathrm{U})$, oxacilina $(5 \mu \mathrm{g})$, tetraciclina $(30 \mu \mathrm{g})$, cloranfenicol $(30 \mu \mathrm{g})$, ampicilina $(10 \mu \mathrm{g})$, eritromicina $(15 \mu \mathrm{g})$, cefalotina $(30 \mu \mathrm{g})$, gentamicina $(10 \mu \mathrm{g})$, amicacina $(30 \mu \mathrm{g})$, novobiocina $(5 \mu \mathrm{g})$, cefotaxima (30 $\mu \mathrm{g})$, ceftazidima $(30 \mu \mathrm{g})$, vancomicina $(30 \mu \mathrm{g})$ e teicoplanina $(30 \mu \mathrm{g})$. Os discos utilizados para o estudo foram produzidos pela Cecon. A linhagem de $S$. aureus ATCC 25923 foi utilizada como controle, conforme recomendação do NCCLS.

\section{Resultados}

\section{Identificação de estafilococos coagulase-negativos}

Na Figura 1 estão expostos os resultados da distribuição das amostras de ECN isoladas segundo a espécie. O $\mathrm{S}$. epidermidis foi a espécie mais freqüentemente isolada, constituindo $77,8 \%$ da população estudada. Os isolados restantes foram distribuídos entre S. haemolyticus (6\%), S. lugdunensis (6\%), S. hominis (4,3\%), S. simulans (3,4\%), S.warneri $(1,7 \%)$ e S. xylosus $(0,8 \%)$.

\section{Estudo da produção de $\beta$-lactamase e sensibilidade às drogas antimicrobianas}

Das 117 amostras de ECN isoladas, 84 (71,8\%) foram produtoras de $\beta$-lactamase (Figura 2), com a detecção da enzima em linhagens de S. epidermidis, S. haemolyticus, S. lugdunensis, S. hominis, S. simulans e S. warneri.

Com referência ao estudo da sensibilidade às drogas, somente duas $(1,7 \%)$ das linhagens de ECN foram sensíveis às 14 drogas testadas, enquanto que $74(63,2 \%)$ foram resistentes a cinco ou mais drogas.

A análise dos resultados para S. epidermidis demonstrou que os maiores percentuais de resistência foram observados em relação à penicilina (94,5\%), ampicilina $(92,3 \%)$, gentamicina (78\%) e ceftazidima (70,3\%). Para esta espécie, os menores percentuais de resistência foram observados com cefalotina $(7,7 \%)$ e novobiocina (6,5\%), não tendo sido caracterizadas amostras resistentes a vancomicina e teicoplanina (Figura 3). Entretanto foi observada uma linhagem de S. epidermidis que apresentou sensibilidade moderada à teicoplanina.

As Figuras 4 e 5 e a Tabela apresentam a resistência antimicrobiana das demais espécies de ECN isoladas. A análise desses resultados também revelou que as drogas menos eficazes foram a penicilina, a ampicilina, a gentamicina e a ceftazidima. Os antimicrobianos mais eficazes para estes microorganismos foram a novobiocina, a cefa- 


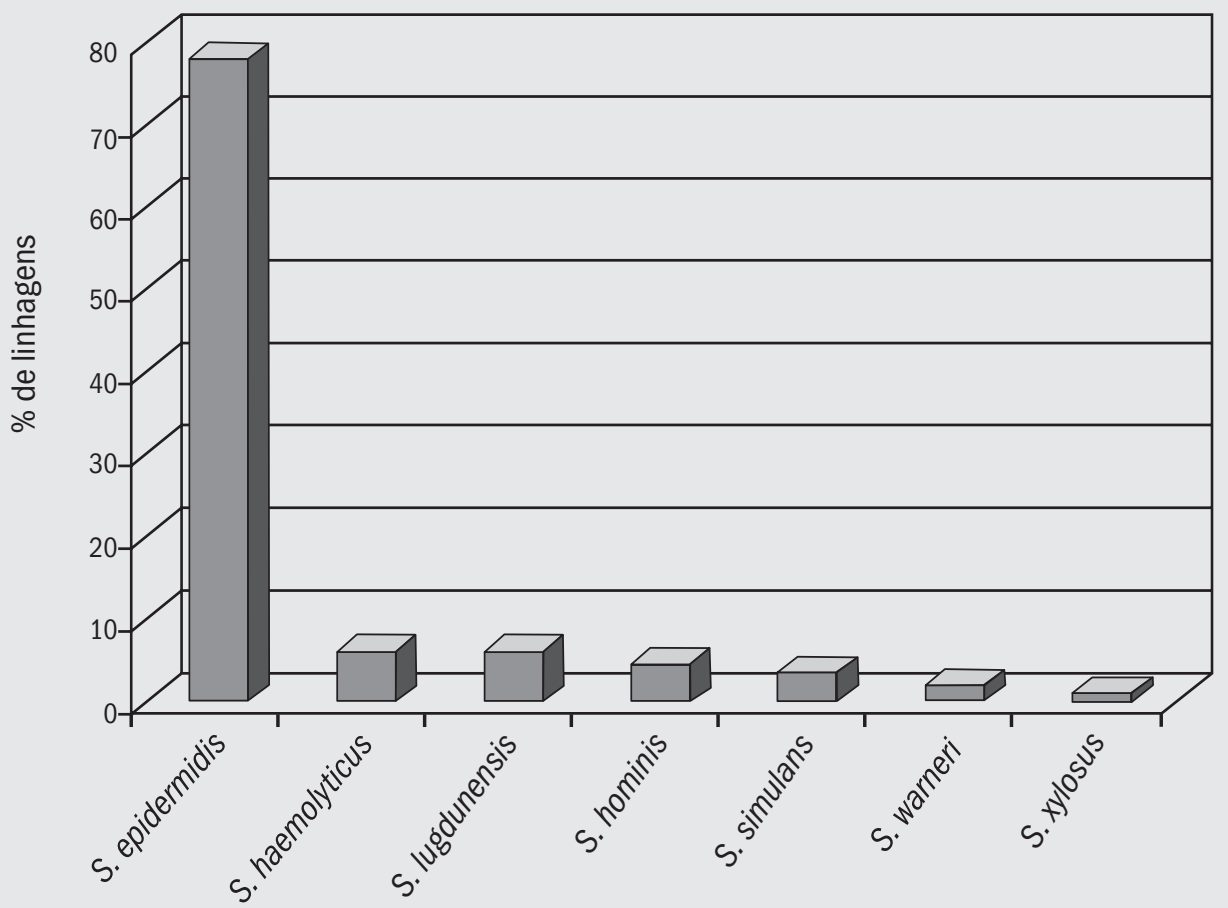

Figura 1 - Distribuição das espécies de ECN isoladas de recém-nascidos

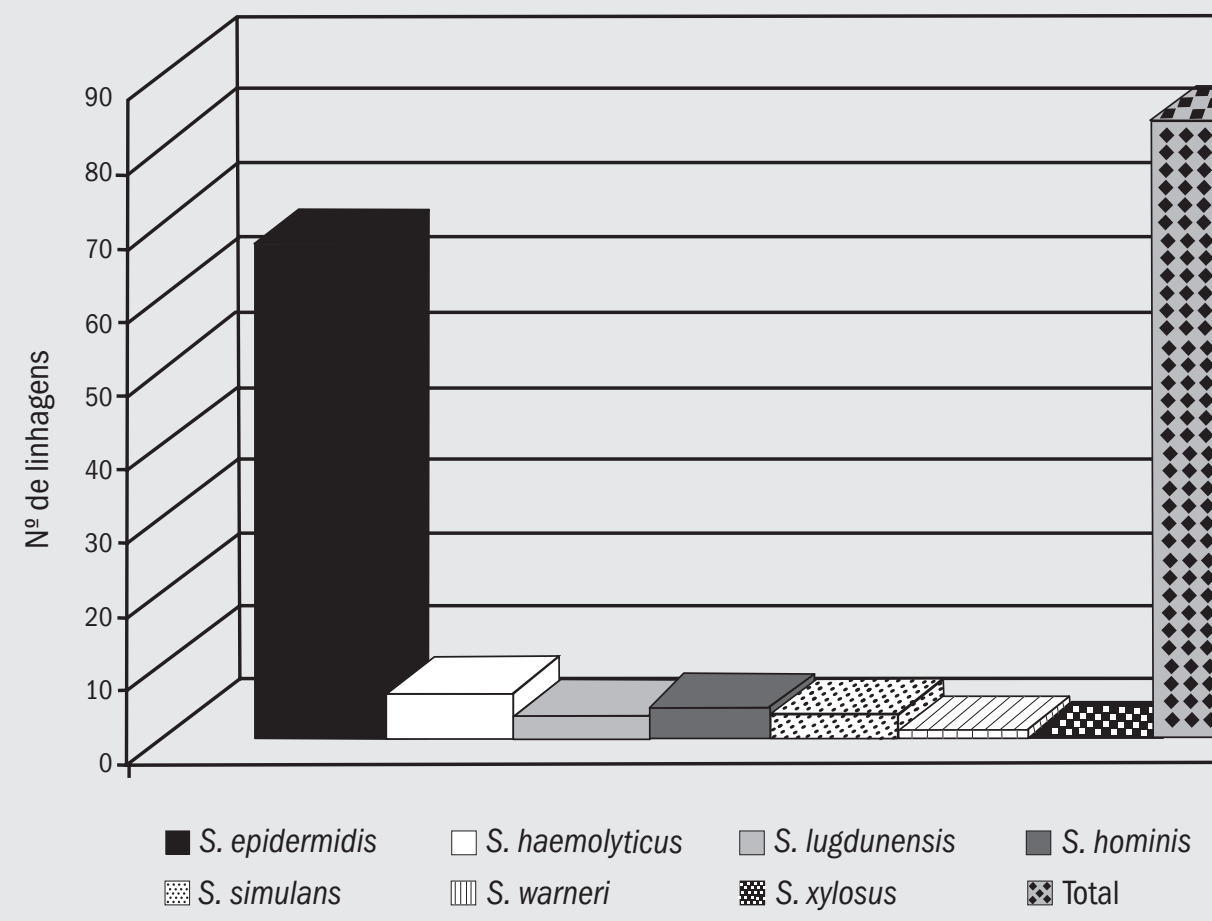

Figura 2 - Frequiencia de linhagens de ECN produtoras de $\beta$-lactamase 


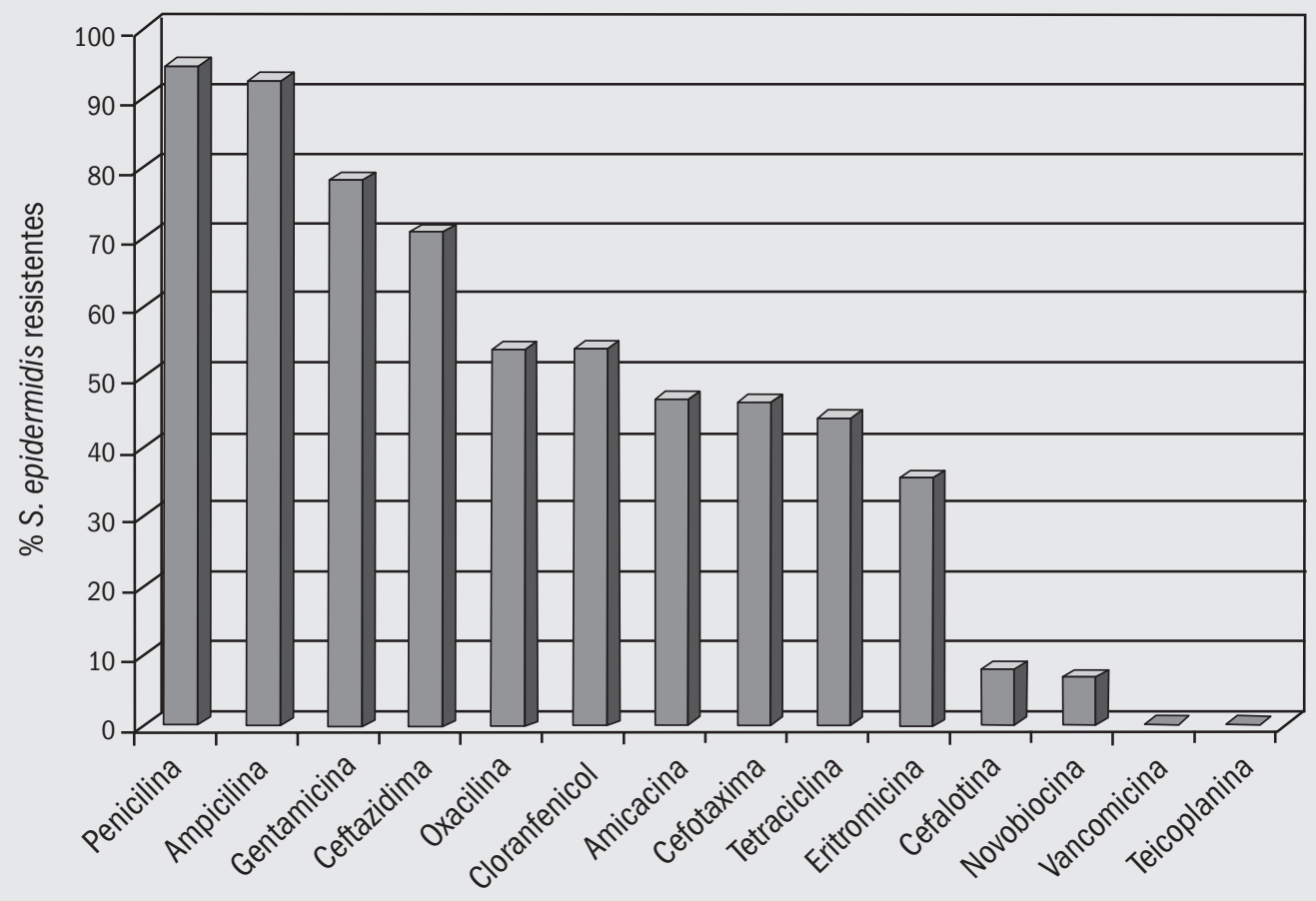

Figura 3 - Resistência às drogas apresentada pelas linhagens de S. epidermidis

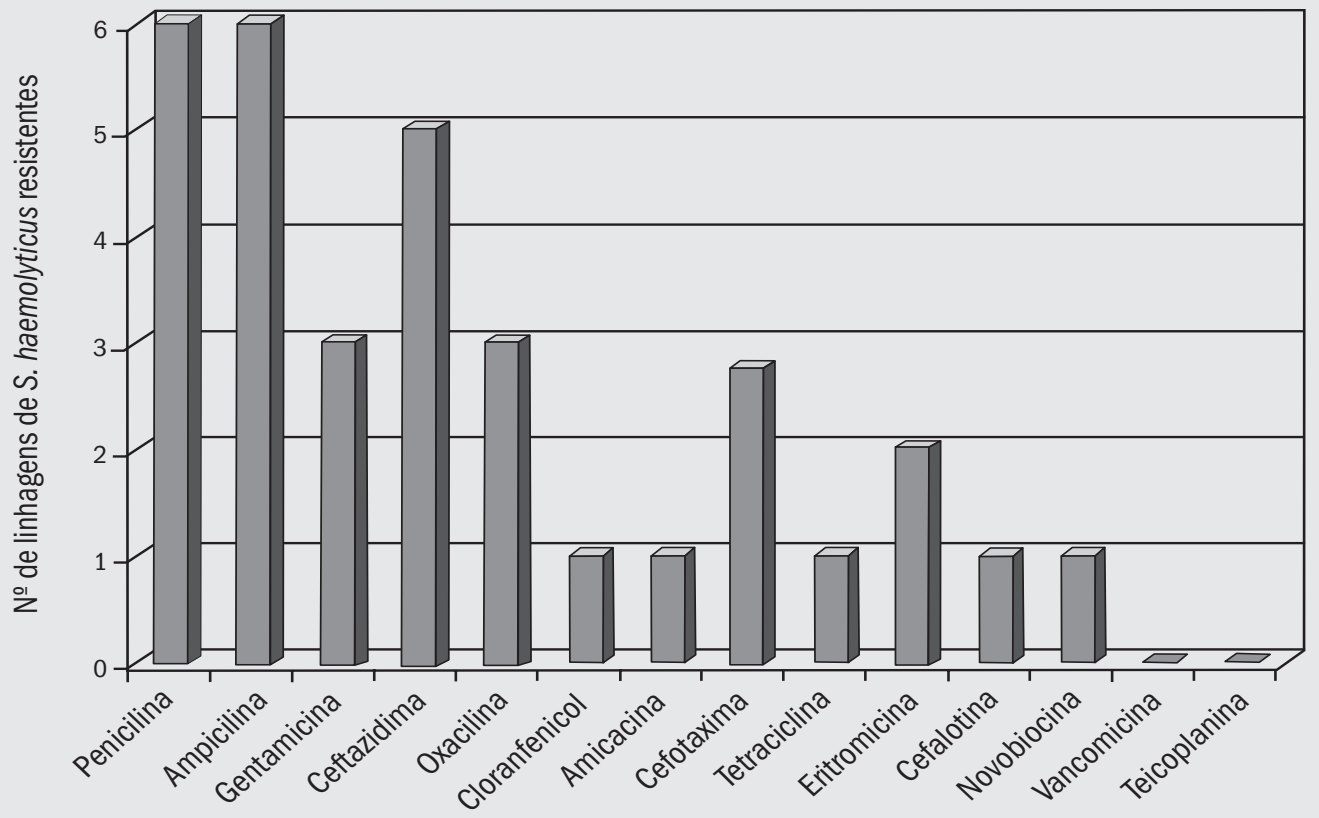

Figura 4 - Resistência às drogas apresentada pelas linhagens de S. haemolyticus 


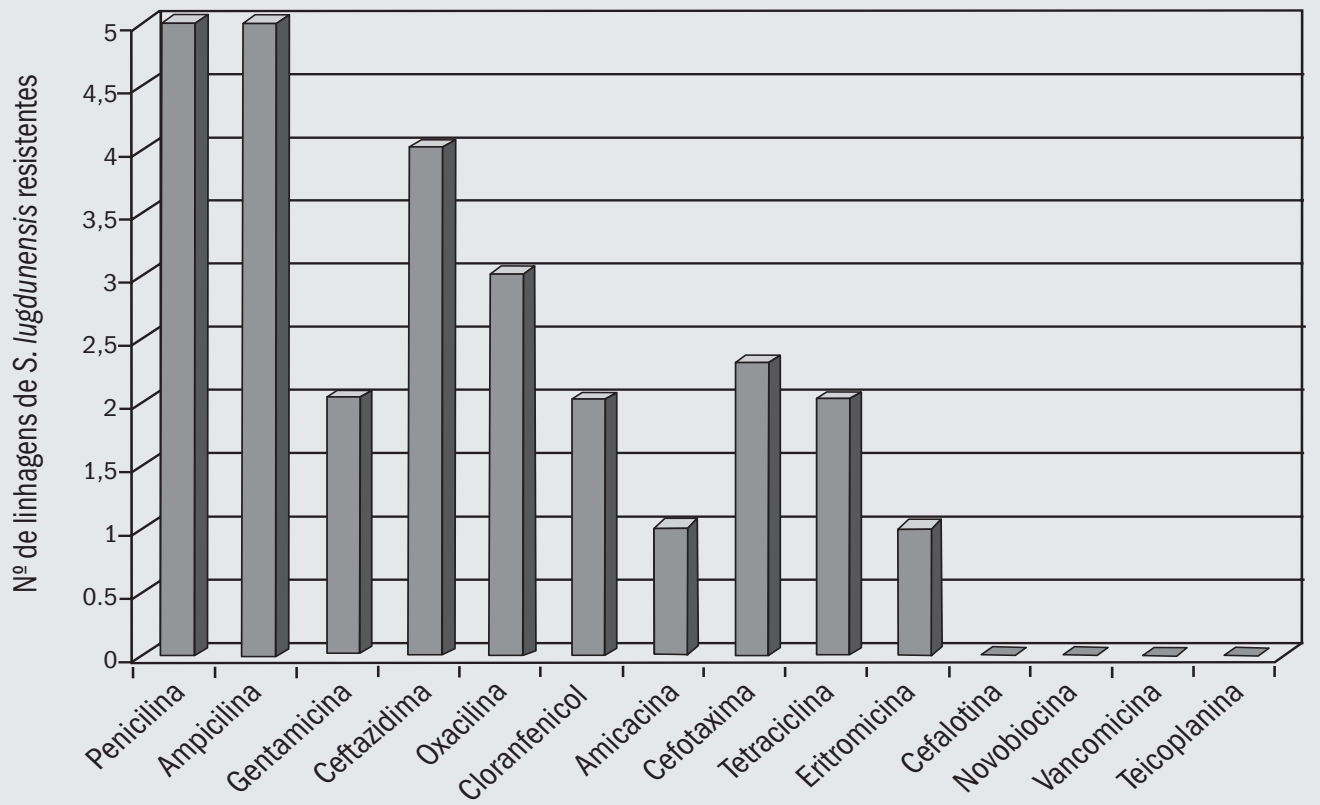

Figura 5 - Resistência às drogas apresentada pelas linhagens de S. lugdunensis

Resistência de $S$. hominis, S. simulans, S. warneri e $S$. xylosus às 14 drogas

Tabela

\begin{tabular}{|c|c|}
\hline Antibióticos & $\begin{array}{c}\text { S. hominis } \\
n=5\end{array}$ \\
\hline Penicilina & 4 \\
\hline Ampicilina & 4 \\
\hline Gentamicina & 4 \\
\hline Ceftazidima & 4 \\
\hline Oxacilina & 2 \\
\hline Cloranfenicol & 3 \\
\hline Amicacina & 4 \\
\hline Cefotaxima & 2 \\
\hline Tetraciclina & 1 \\
\hline Eritromicina & 3 \\
\hline Cefalotina & 0 \\
\hline Novobiocina & 0 \\
\hline Teicoplanina & 0 \\
\hline Vancomicina & 0 \\
\hline
\end{tabular}

$\begin{array}{ll}3 & 4 \\ 3 & 1 \\ 3 & 0 \\ 2 & \\ 1 & 2 \\ 1 & 0 \\ 3 & \\ 1 & 0 \\ 1 & \\ 2 & 1 \\ 0 & 0 \\ 1 & 0 \\ 0 & 0 \\ 0 & 0\end{array}$

1
0
0
1
1
0
0
1
0
0
1
1
0
0

$0 \quad 0$

Espécies de ECN resistentes às drogas

$\begin{array}{lc}\text { S. simulans } & \text { S. warneri } \\ n=4 & n=2\end{array}$

S. $x y l o s u s$

Total

$n=12$ 
lotina, a vancomicina e a teicoplanina, caracterizando-se apenas uma linhagem de S. haemolyticus e uma de S. xylosus resistentes à cefalotina e nenhuma à vancomicina e à teicoplanina.

Os maiores percentuais de resistência dos $117 \mathrm{ECN}$ às 14 drogas testadas foram observados em relação à penicilina (90,6\%), à ampicilina (88,9\%), à gentamicina $(70,9 \%)$, à ceftazidima (70\%), à oxacilina (50,4\%), ao cloranfenicol $(47,9 \%)$, à amicacina (44,1\%), à cefotaxima (43,6\%), à tetraciclina $(39,3 \%)$ e à eritromicina (35\%) (Figura 6).

A Figura 7 mostra a freqüência de amostras de ECN multirresistentes, consideradas através do critério de resistência a cinco ou mais drogas testadas. Das 91 linhagens de S. epidermidis isoladas, $60(65,9 \%)$ demonstraram ser multirresistentes.

Com relação às demais espécies, quatro das sete linhagens de S. haemolyticus isoladas, duas de sete cepas de S. lugdunensis, quatro de cinco $S$. hominis, duas de quatro S. simulans, uma de duas linhagens de S. warneri e o único isolado de $S$. xylosus apresentaram-se multirresistentes.

\section{Discussão}

Os estafilococos coagulase-negativos constituem importantes microrganismos integrantes da microflora nor- mal do homem e, nos últimos anos, têm emergido como agentes etiológicos de uma série de infecções $(18,21)$.

Nossas observações em 117 linhagens indicaram o S. epidermidis como a espécie mais freqüentemente isolada $(77,8 \%)$, fato que corresponde ao relato de outros autores $(12,21)$. A predominância de S. epidermidis entre as espécies de ECN causadoras de infecções em recém-nascidos tem sido reconhecida por outros investigadores, com sua freqüência variando entre $60 \%$ e $90 \%$ destes casos (12).

Os ECN isolados de espécimes clínicos são freqüentemente resistentes aos antibióticos usados no âmbito hospitalar $(11,21)$. A elevada transferência de genes de resistência entre linhagens (22) e o uso abusivo de drogas antimicrobianas têm se constituído em importantes fatores para a seleção de amostras multirresistentes (14).

Em nosso estudo, somente duas $(1,7 \%)$ das linhagens estudadas foram sensíveis às 14 drogas testadas. Esta freqüência foi consideravelmente mais baixa do que a de $8,2 \%$ mostrada por Barcs et al. (6), observando-se, contudo, uma taxa de multirresistência de $63,2 \%$, similar à encontrada pelos autores mencionados anteriormente.

A maioria das linhagens estudadas apresentou resistência à penicilina $(90,6 \%)$ e à ampicilina $(88,9 \%)$. As $\beta$-lactamases produzidas por esses microorganismos são responsáveis pela maioria da resistência a penicilina $G$ e

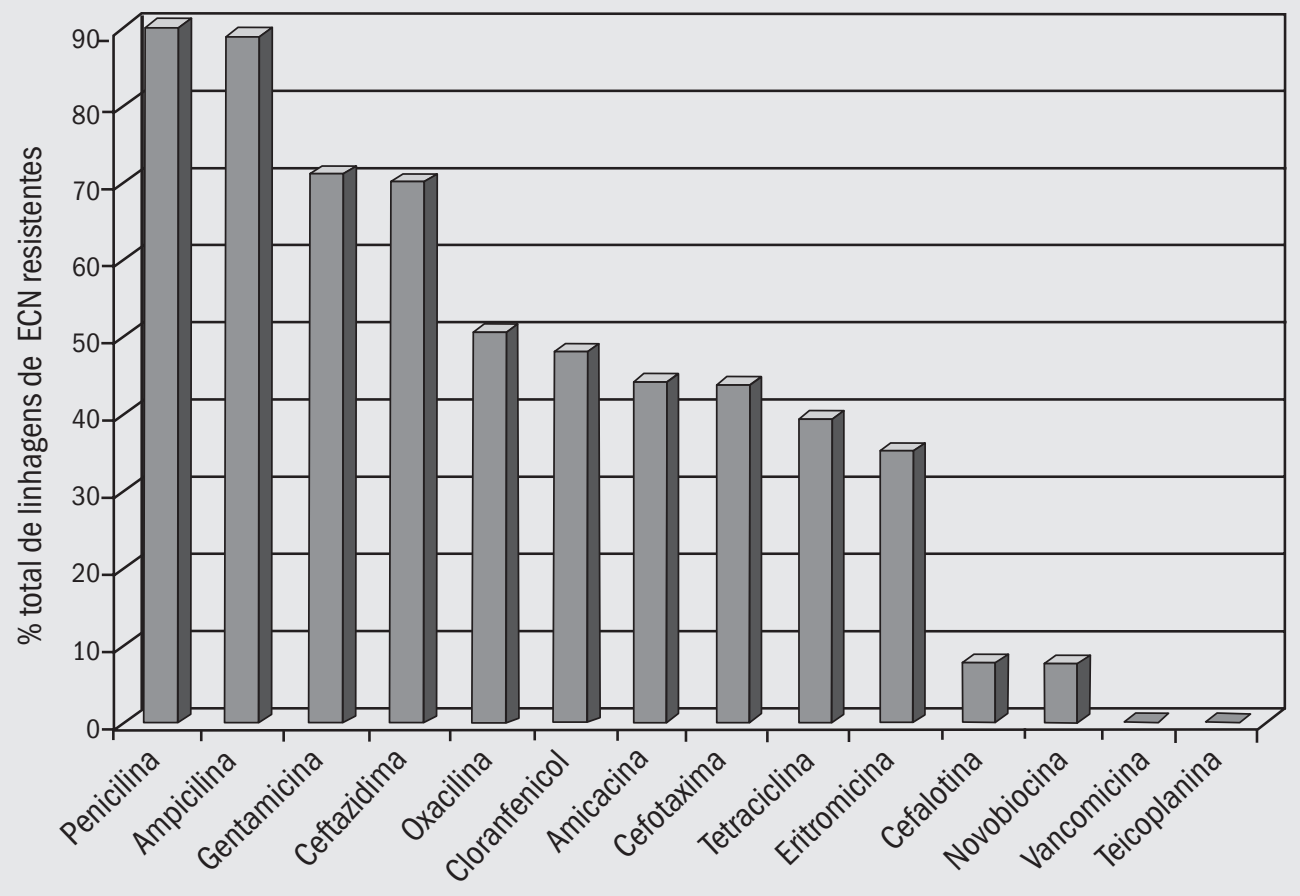

Figura 6 - Resistência às drogas apresentada pelas linhagens de ECN 


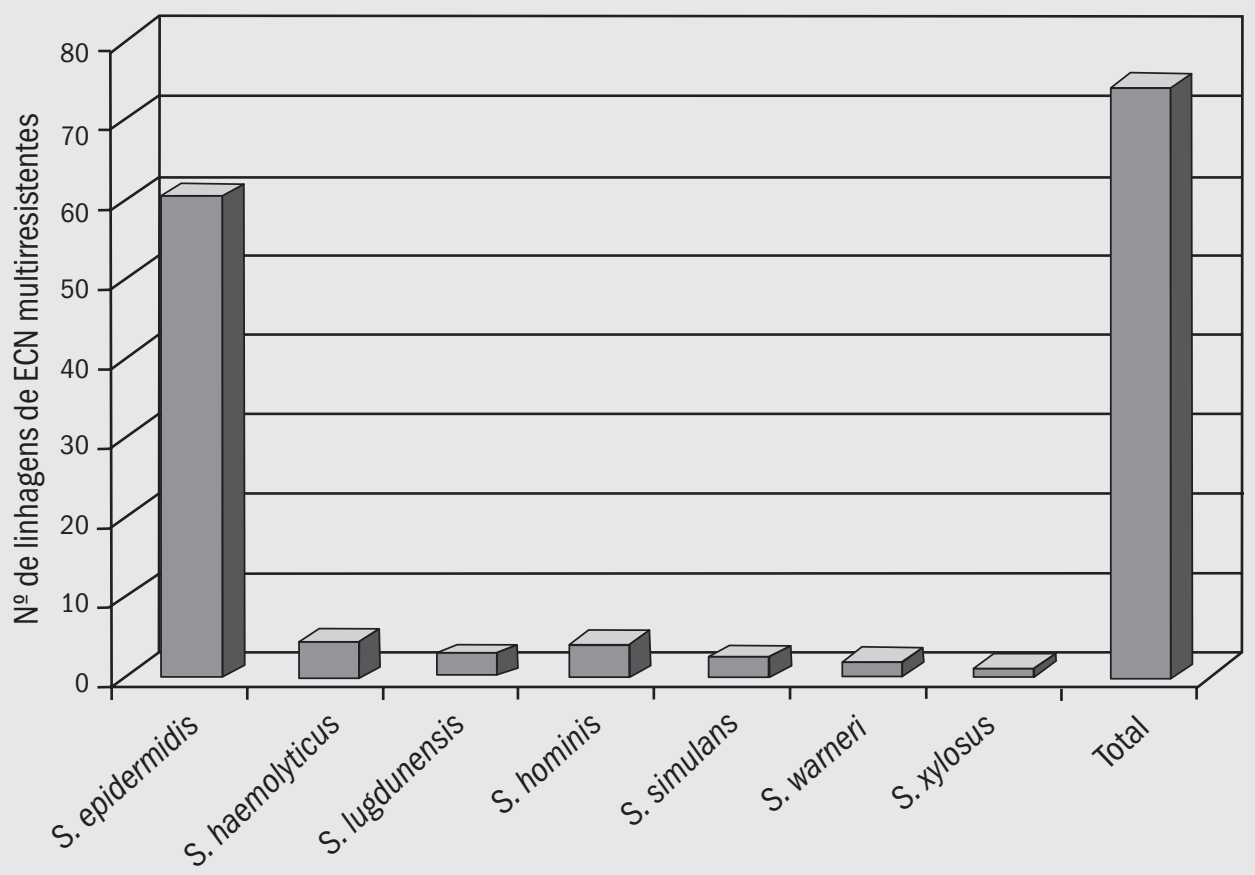

compostos relacionados. Segundo Archer \& Climo (3), assim como o S. aureus, $80 \%$ a $90 \%$ das linhagens de ECN produzem $\beta$-lactamase. Neste estudo foi constatada a produção de $\beta$-lactamase por $84(71,8 \%)$ das linhagens de ECN estudadas, não sendo observada diferença entre as espécies de ECN quanto à produção desta enzima. Este achado já era esperado, uma vez que todas as linhagens são de origem hospitalar e a produção dessas enzimas é induzida pela exposição às penicilinas. Em estudo realizado por Bergan \& Lernestedt (7), observou-se uma maior percentagem de produção de $\beta$-lactamase por linhagens obtidas no ambiente hospitalar do que por linhagens obtidas na comunidade.

Nossos resultados revelaram uma resistência à oxacilina em $50,4 \%$ das linhagens estudadas, índice similar ao relatado por Jones (14), e uma atividade antimicrobiana superior da cefalotina em relação às cefalosporinas de terceira geração (ceftazidima e cefotaxima), constatando-se que apenas $7,7 \%$ das linhagens revelaram-se resistentes a essa droga, dado concordante com os obtidos por outros autores (19). Entretanto, segundo o NCCLS (24), há evidências clínicas que isolados de estafilococos que são resistentes à oxacilina não respondem in vivo ao tratamento com cefalosporina, devendo, portanto, ser relatados como resistentes a todas as cefalosporinas.
Assim como aos $\beta$-lactâmicos, a resistência aos aminoglicosídeos também tem emergido entre os ECN, com $70,9 \%$ das linhagens estudadas resistentes à gentamicina e $44,1 \%$ à amicacina. Resultados similares foram verificados por Archer \& Scott (2), com mais de $60 \%$ dos ECN isolados de várias fontes clínicas resistentes a esta droga. Segundo Archer \& Climo (3), os ECN transportam genes que codificam enzimas inativadoras de aminoglicosídeos, assim como o $S$. aureus.

Similarmente ao encontrado por outros autores (27), as linhagens isoladas neste estudo mostraram resistência múltipla aos antibióticos, mas todos os isolados foram sensíveis à vancomicina e à teicoplanina, com somente uma linhagem de S. epidermidis apresentando sensibilidade moderada à teicoplanina. A diminuição da suscetibilidade de linhagens de $S$. haemolyticus e S. epidermidis à teicoplanina tem sido relatada por outros autores $(5,29)$. Embora sejam raras, estas linhagens podem ser o sinal do início da resistência a um importante antibiótico usado no tratamento das infecções estafilocócicas.

Entretanto os mecanismos responsáveis pela resistência dos ECN a esses glicopeptídeos não estão completamente esclarecidos (8). Portanto precauções devem ser tomadas para prevenir a disseminação de linhagens resistentes no ambiente hospitalar, reservando o uso 
desses antibióticos para os casos mais severos de infecção por ECN.

Em vários laboratórios clínicos de rotina a identificação presuntiva de $S$. saprophyticus é baseada somente na resistência à novobiocina. Entretanto tem sido reconhecido que outras espécies de ECN, incluindo $S$. cohnii, S.sciuri e S. xylosus, são também resistentes à novobiocina na concentração de $5 \mu \mathrm{g}(13)$.

Por outro lado, a resistência aos antibióticos é geralmente codificada por plasmídios, e dessa forma é possível a transferência de genes resistentes à novobiocina entre espécies (23). Neste estudo, seis linhagens de $S$. epidermidis, uma de $S$. haemolyticus, uma de $S$. simulans e uma de $S$. xylosus demonstraram resistência à novobiocina, confirmando a observação de Large et al. (20) de que outras espécies de ECN também podem apresentar resistência a essa droga. Esses resultados sugerem que provas adicionais, incluindo fermentação de carboidratos e outros testes, devem ser usadas em conjunto com a prova de sensibilidade à novobiocina para a correta identificação de espécies de ECN.

Quanto à multirresistência, não foi observada diferença entre as espécies de ECN. Esses resultados estão associados com a origem hospitalar das linhagens e refletem a seleção de organismos resistentes que comumente ocorre no ambiente hospitalar, bem como a transferência de genes de resistência entre linhagens de ECN (11). Vários autores enfatizam que esses microrganismos são reservatórios de vários genes de resistência, já que são os maiores componentes da microflora da pele e mucosas e, portanto, estão mais sujeitos à pressão seletiva dos antimicrobianos usados comumente $(1,26)$.

Em conclusão, nossos resultados demonstraram que a maioria das linhagens de ECN isoladas de processos infecciosos em recém-nascidos apresenta multirresistência, dificultando a terapêutica das infecções causadas por esses microrganismos, além da possibilidade da transferência desses genes para linhagens de $S$. aureus, mais virulentas.

\section{Referências}

I. Archer, G.L. Molecular epidemiology of multiresistant Staphylococcus epidermidis. I. Antimicrob. Chemother., 21 : 338,1988

2. Archer, G.L. \& Scott, J. Conjugative transfer genes in staphylococcal isolates from the United States. Antimicrob. Agents Chemother., 35: 2500-4, 1991.

3. Archer, G.L. \& Climo, M.W. Antimicrobial susceptibility of coagulase-negative staphylococci. Antimicrob. Agents Chemother., 38: 2231-7, 1994.

4. Baker, J.S. Comparison of various methods for differentiation of staphylococci and micrococci. J. Clin. Microbiol., 19: 875-9, 1984.

5. Bannerman, T.L.; Wadiac, D.L. \& Kloos, W.E. Susceptibility of Staphylococcus species and subspecies to teicoplanin. Antimicrob. Agents Chemother., 35: 1919-22, 1991.

6. Barcs, I.; Vályi-Nagy, T. \& Pánovics, J. Clinical occurrence and virulence testing of coagulase-negative staphylococci. Acta Microbiol. Hung.,36: 4I5-24, 1989.

7. Bergan,T.\& Lernestedt, J.O.Antibiotic resistance in staphylococci from a hospital environment. Chemotherapy, 29:28-36, 1983.

8. Bischoff, M. et al. Involvement of multiple genetic loci in Staphylococcus aureus teicoplanin resistance. FEMS Microb. Let., 194: 77-82, 2001.

9. Evans, J.B.; Bradford Junior,W.L. \& Niven Junior, C.F. Comments concerning the taxonomy of the genera micrococcus and staphylococcus. Int. Bull. Bacteriol. Nomencl. Taxon., 5: 61 -6, 1955.

10. Golledge, C.L. Staphylococcus saprophyticus bacteremia.J. Infect. Dis., 157:215, 1988
I I. Grosserode, M.H. \& Wenzel, R.P. The continuing importance of staphylococci as major hospital pathogens.J. Hosp. Infect. 19:3-17, |991.

12. Hudome, S.M. \& Fisher, M.C. Nosocomial infections in the neonatal intensive care. Curr. Op. in Infect. Dis., 14: 303-7. 2001.

13. Hussain, Z. et al. Comparison of the MicroScan system with the "API Staph-Ident" system for species identification of coagulase-negative staphylococci.J. Clin. Microbiol., 23: I26$8,1986$.

14. Jones, R.N. Impact of changing pathogens and antimicrobial susceptibility patterns in the treatment of serious infections in hospitalized patients. Am. J. Med., 100: I - 12, 1996.

15. Jordan, P.A. et al. Urinary tract infection caused by Staphylococcus saprophyticus. J. Infect. Dis., 142: 510-5, 1980.

16. Kloos, W.E. \& Schleifer, K.H. Simplified scheme for routine identification of human Staphylococcus species. J. Clin. Microbiol., 1: 82-8, 1975.

17. Kloos, W.E. \& Bannerman,T.L. Update on clinical significance of coagulase-negative staphylococci. Clin. Microbiol. Rev., 7: I 17 40, 1994.

18. Kloos, W.E. \& Bannerman, T.L. Staphylococcus and Micrococcus. In: Murray, P.R. et al. (ed.) Manual of Clinical Microbiology. 6. ed.Washington:American Society Microbiology, 1995. p. 282-98.

19. Kotilainen, P:; Nikoskelainen, I. \& Huovinen, P.Antibiotic susceptibility of coagulase-negative staphylococcal blood isolates with special reference to adherent, slime-producing Staphylococcus epidermidis strains. Scand. J. Infect. Dis., 23: 325-32, I991. 
20. Large, M. et al. A study of coagulase-negative staphylococci isolated from clinically significant infections at an australian teaching hospital. Pathology, 21 : 19-22, 1989.

21. Marshall, S.A. et al. Staphylococcus aureus and coagulase-negative staphylococci from blood stream infections: frequency of occurence, antimicrobial susceptibility, and molecular (mecA) characterization of oxacillin resistance in the SCOPE program. Diagn. Microbiol. Infect. Dis., 30: 205-14, 1998.

22. Mcdonnell, R.W.; Sweeney, H.M. \& Cohen, S. Conjugational transfer of gentamicin resistance plasmids intra- and interspecifically in Staphylococcus aureus and Staphylococcus epidermidis.Antimicrob.Agents Chemother., 23: I 5 |-60, 1983.

23. Mctaggart, L.A. \& Elliott,T.S.J. Is resistance to novobiocin a reliable test for confirmation of the identification of Staphylococcus saprophyticus? J. Med. Microbiol., 30: 253-66, 1989.

24. National Committee for Clinical Laboratory Standards (NCCLS). Performance standards for antimicrobial disk susceptibility tests. Approved Standard M2-A7. 7. ed. Villanova, 2000.

25. Nickel, J.C.\& Costerton, J.W. Coagulase-negative Staphylococcus in chronic prostatitis. J. Urol., 147: 398-401, 1992.

26. Pfaller, M.A. \& Herwaldt, L.A. Laboratory, clinical, and epidemiological aspects of coagulase-negative staphylococci. Clin. Microbiol. Rev., I: 28I-99, 1988.

27. Refsahl, K. \& Andersen, B.M. Clinically significant coagulasenegative staphylococci: identification and resistance patterns. J. Hosp. Infect., 22: 19-31, 1992.

28. Schaberg, D.R., Culver, D.H. \& Gaynes, R.P. Major trends in the microbial etiology of nosocomial infection. Am. J. Med., 91: 72-5, 1991.

29. Veach, L.A. et al. Vancomycin resistance in Staphylococcus haemolyticus causing colonization and bloodstream infection. J. Clin. Microbiol., 28: 2064-8, 1990. 